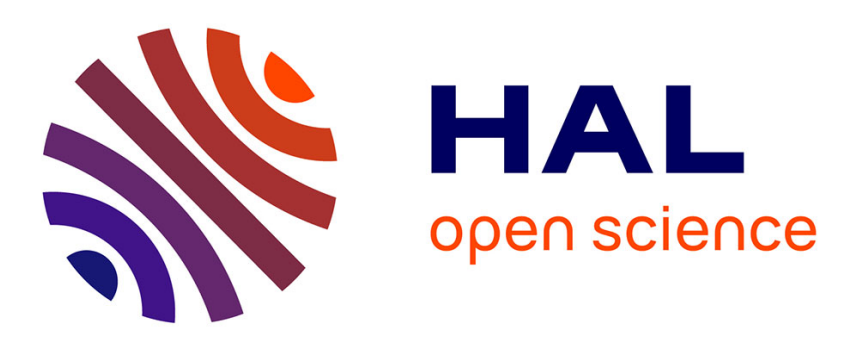

\title{
Allocation of Transportation Cost \& CO2 Emission in Pooled Supply Chains Using Cooperative Game Theory
}

\author{
Xiaozhou Xu, Shenle Pan, Eric Ballot
}

\section{To cite this version:}

Xiaozhou Xu, Shenle Pan, Eric Ballot. Allocation of Transportation Cost \& CO2 Emission in Pooled Supply Chains Using Cooperative Game Theory. INCOM 2012, May 2012, Bucharest, Romania. hal-00733491

HAL Id: hal-00733491

https://hal-mines-paristech.archives-ouvertes.fr/hal-00733491

Submitted on 18 Sep 2012

HAL is a multi-disciplinary open access archive for the deposit and dissemination of scientific research documents, whether they are published or not. The documents may come from teaching and research institutions in France or abroad, or from public or private research centers.
L'archive ouverte pluridisciplinaire HAL, est destinée au dépôt et à la diffusion de documents scientifiques de niveau recherche, publiés ou non, émanant des établissements d'enseignement et de recherche français ou étrangers, des laboratoires publics ou privés. 


\title{
Allocation of Transportation Cost \& $\mathrm{CO}_{2}$ Emission in Pooled Supply Chains Using Cooperative Game Theory
}

\author{
Xiaozhou. Xu* Shenle. Pan ${ }^{* *}$ Eric. Ballot ${ }^{* * *}$ \\ * Mines ParisTech, CGS and CAOR, 75272, Paris, France, (e-mail: \\ xiaozhou.xu@mines-paristech.fr) \\ ** Mines ParisTech, CGS, 75272, Paris, France, (e-mail: \\ shenle.pan@mines-paristech.fr) \\ *** Mines ParisTech, CGS, 75272, Paris, France, (e-mail: \\ eric.ballot@mines-paristech.fr)
}

\begin{abstract}
The sustainability of supply chain,both economical and ecological, has attracted intensive attentions of academic and industry. It is proven in former works that supply chain pooling given by horizontal cooperation among several independent supply chains create a new common supply chain network that could reduce the costs and the transport $\mathrm{CO}_{2}$ emissions. In this regard, this paper introduces a scheme to share in a fairly manner the savings. After a summary of the concept of pooled-supply-networks optimization and $\mathrm{CO}_{2}$ emission model, we use cooperative game theory as the cooperative mechanism for the implementation of the horizontal pooling. Since we proved the related pooling game to be super-additive, a fair and stable allocation of common gain in transportation cost and $\mathrm{CO}_{2}$ emission is calculated by Shapley Value concept. Through a case study, the results show that supply chains pooling can result in reductions of both transportation cost and carbon emissions, and that the increase of carbon-tax rate gives enterprises more incentives for the implementation of such pooling scheme.
\end{abstract}

Keywords: Supply chains pooling, Sustainable supply chain, Transportation, $\mathrm{CO}_{2}$ emission, Cooperative game theory, Shapley Value

\section{INTRODUCTION}

The supply chain sustainability, both economical and ecological, has been considered as important criteria of supply chain evaluation, and it is these two aspects of sustainability that we studied in this work. Among different aspects of a whole supply chain, transportation is an important activity to be investigated for promoting the supply chain sustainability due to greater transportation distances and bigger portion of both cost and $\mathrm{CO}_{2}$ emission represented by this activity.

About the appropriate means for cost and emission reduction, the supply chains pooling, an innovative form of organization that will be detailed later, is such an approach that defines a common logistics system involving shippers of different supply chains to increase the supply chain efficiency. It is developed on the basis of supply networks merging concept. In previous research, the significant improvement of economical and/or ecological performance achieved by this type of organization has been showed. See Cruijssen et al. (2007) and Ballot and Fontane (2010).

Since the supply chains pooling can achieve the economical and ecological efficiency improvement, naturally there arise the incentives for such cooperation. Before all operators being convinced to form a coalition, and thus to organize their transportation, even design their logistics network cooperatively in this common system for reducing
$\mathrm{CO}_{2}$ emission, the payoff-allocation criterion must be well defined antecedently. This problem is covered by the cooperative game theory, a branch of the Game Theory that has been founded by the famous work of Von Neumann et al. (2007). In this paper, we will show that this theory can bring us an instructive decision framework for the implementation of the logistics pooling.

The contribution of this article is as follows. At first, we describe a supply chains pooling scheme for cooperating among supply networks. Secondly, we develop an optimization model for the pooled supply networks to reduce the total cost, which consist of transportation cost and carbon tax. Then, through a case study, we assess the sensitivity of pooling optimization to the tax rate, and found that the carbon tax gives incentive for pooling. Thirdly, we define the cooperative pooling game to investigate the cooperating mechanism lies in the implementation of this pooling scheme, and prove the super-additivity of such game. At last, we propose a reasonable and stable imputation by adopting the Shapley Value concept to allocate the savings in the corresponding pooling game.

The article is organized as follows. In Part 2, we will present the pooling concept and the supply chains pooling developed on this basis. In Part 3, the preliminary of cooperative game theory and some important concepts therein will be introduced. In Part 4, we will introduce the supply-chains-pooling optimization problem studied 
and the setting of corresponding game. Then we will investigate a real-world case of a retail supply chains network we have optimized and studied in Part 5. At last, we will summarize the insights achieved by this article in Part 6.

\section{SUPPLY CHAINS POOLING: AN INNOVATIVE FORM OF COLLABORATION TOWARDS SUSTAINABILITY}

\subsection{Pooling approaches to sustainability}

Today, enterprises cannot ignore the environmental issue in their business activities. The increasing government regulation and stronger public mandates of the environmental accountability take this issue onto the enterprises' agenda. Vanek and Morlok (2000) showed that the transportation, which is intensively used in supply chain, is one of the biggest contributors of the carbon emission. In France, road vehicles represent $30 \%$ of all $\mathrm{CO}_{2}$ emissions, with $15 \%$ by trucks (domestic freight trains, ships and planes account for between $1 \%$ and $2 \%$ of emissions) as to CITEPA (2009). A survey by Léonardi and Baumgartner (2004) established a very strong correlation between transportation efficiency and $\mathrm{CO}_{2}$ emissions. Therefore, improving freight transportation efficiency will help reduce one of the major sources of $\mathrm{CO}_{2}$ emissions.

Grouping freights together to consolidate them is a relatively old idea for improving transportation efficiency. Thus Hall (1987) and Pooley and Stenger (1992) defined several forms of consolidation: warehouses consolidation, cross-docking consolidation platforms and consolidation at the level of means of transportation. These forms of consolidation are essentially evidenced at the level of transport operations.

However, at the level of supply or distribution networks, they are designed by each company (manufacturer or retailer) separately. As a result, transportation resources are significantly underused and the overall volume is growing, thus entering into contradiction with environment objectives, as illustrated in the work of McKinnon and Piecyk (2009).To improve the efficiency of goods transportation, it has been realized that collaboration between these independent supply chains could be a possible solution.

Horizontal cooperation was applied to large-scale logistics for the first time in Cruijssen and Salomon (2004) who used a case study of flower transportation in the Netherland as a basis. They found that sharing transportation orders at IT level between carriers generated transportation cost savings generally varying between 5 and $15 \%$. In a similar manner, Ergun et al. (2007) covered collaboration between shippers and showed that it enabled the hidden costs linked to transportation by service companies to be reduced, reducing trips when running empty in order to reposition lorries. To confirm the potential advantage of horizontal cooperation at logistics level, Cruijssen et al. (2007) conducted a survey of close to 162 Flemish companies, $75 \%$ of which mentioned that this cooperation strategy could increase company productivity.

According to the results shown above, collaboration, specially horizontal cooperation, is therefore a solution to improve logistics, transportation efficiency in particular, both economically and ecologically. It is in this context that pooling is proposed and studied. There exist very few articles on the impact of collaboration on logistics pooling, and the related environmental impact. However, since the cooperative logistics pooling is proved to be an effective approach to the improvement of transportation efficiency, specially fuel efficiency and fill rate, as demonstrated above, we can naturally deduce that it is an approach, which, by its efficiency, can encounter also sustainable development issues, as showed in the work of Pan et al. (2010).

\subsection{Supply networks pooling}

An example of supply networks pooling is displayed in Fig. 1. Firstly, classic supply chain networks for retail distribution, in which each actor has his dedicated network, is illustrated in the top part of Fig. 1. In relation to this system, pooling is carried out if, and only if, it improves operation of the supply chain, for example better fill rate for the lorries ordered in Full Truck Load (FTL) in the network, if we take into account the impact of pooling on transportation only. It was shown by McKinnon et al. (2003) that the fill rate was low (60\%) for downstream flows in particular. Therefore, it is advantageous to study pooled systems. The pooled system described in the lower part of Fig. 1 shows, on the other hand, the grouping of flows. The advantage of this type of system was shown in Pan et al. (2010).

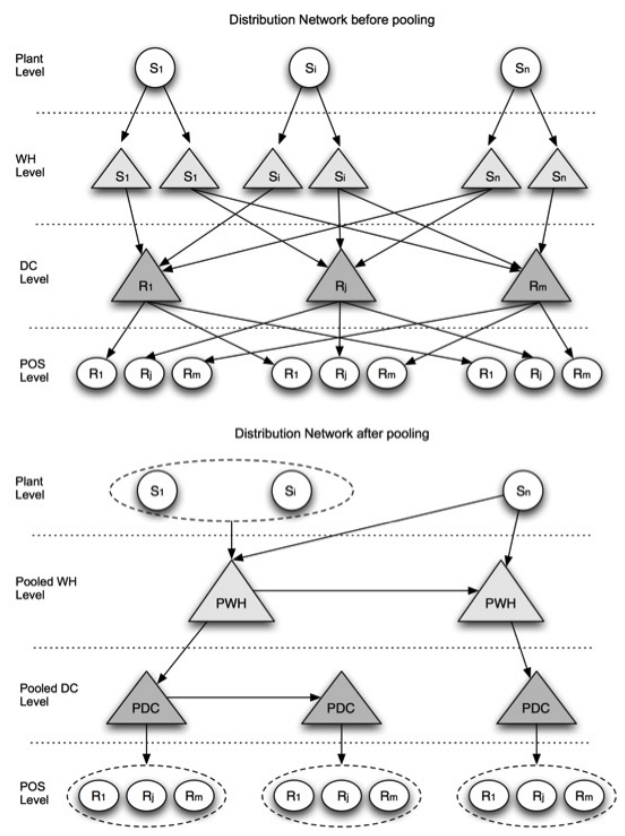

Fig. 1. Illustration of the logistics pooling (Ai: Supplier i; Rj: Retailer j; WH: Warehouse; DC: Distribution Center; POS: Point Of Sale)

The cost optimization of the logistics network was studied as a transportation problem, formulated by a mixed linear integer optimization problem studied in Pan (2010), It involves optimizing the allocation of flows to minimize the transportation cost and other possible additional costs: transfer, opening of a logistics center, stocks, etc. The optimized flows form the optimized network - we can then 
see according to the assignment of the flows carried out, whether or not the pooling of flows is advantageous. By the same procedure, Pan also developed the optimization model for the $\mathrm{CO}_{2}$-emission issue in that work. For more details of implementation, readers who are interested can refer to Pan (2010).

Pan et al. (2010) optimized separately the total transportation cost and the $\mathrm{CO}_{2}$ emission in a pooled supply chains network, using the real data from the industrial practice. As the results shows, this kind of innovative organization is preferable for promoting the supply chains sustainability.

\subsection{Objective of pooling}

In this work, we concern both the economical and environmental sides of the total cost. Due to the actual implementation of carbon tax in European countries, and the international trend on emission control, the reduction of $\mathrm{CO}_{2}$ emission, which will affect both client preference and the level of tax, will become indispensable task for enhancing competitive ability.

So we enhance the cost-optimization model by taking $\mathrm{CO}_{2}$ tax into consideration. We set the objective function of the optimization model as $M I N: C+r \cdot e$, where $C$ denotes the total cost of pooled network incurred by transport activities, $r$ denotes the rate of carbon tax while $e$ denotes the total content of $\mathrm{CO}_{2}$ emitted by transport. For further details about the optimization model, readers who are interested can refer to Pan (2010). This model optimizes the sum of global transportation cost and global emission tax arising in the pooled network.

\subsection{Viability of supply chains pooling}

The pooled transportation systems shown here have an economic advantage but they also enable the environment footprint to be reduced. However, for a reduction of this kind to be implemented, participation in pooled systems must not only be globally economically advantageous but it must be fair for each participant. Moreover, the survey in Cruijssen et al. (2007) mentioned before showed that the main obstacle to the implementation of collaboration resides in the difficulty of constructing mechanisms for fair distribution of the gains between the members of the coalition. The difficulty in finding long-term partners for a win/win relationship is also mentioned by firms answering the survey. These difficulties can also be noted with the implementation of pooling principles. To do this, we will apply cooperative game theory with transferable utility.

\section{TRANSFERABLE UTILITY COOPERATIVE GAME THEORY}

\subsection{Introduction to TU cooperative game theory}

As to Hart et al. (1997), the game theory is divided into two main approaches: the non-cooperative and the cooperative game theory. Cooperative game theory is used in cases where the players can achieve more benefit by cooperating with other players than staying alone, thus it can be aptly applied to investigate the supply chains pooling game.Assuming that the common gain created by pooling can be shared between the players, in this instance pooling is therefore a TU-Cooperative game. In a TUcooperative game, the players are allowed to make binding commitment, which defines how to cooperate as a coalition and how should common profit be shared out.

TU-cooperative game theory properties and notation $\mathrm{A}$ TU-cooperative game can be denoted by $G=(N, v)$, where $N$, called the grand coalition, represents the finite set of players and $v$ is the characteristic function that can be interpreted as the worth of coalitions. We can define a coalition $S$, which is a subset of $N$. For each $S \subseteq N$, $v(S)$ gives the maximum value created by the coalition. As defined by Shapley (1971), the game $G=(N, v)$ is said to be super-additive if the characteristic function satisfies inequation (1).

$$
v(S)+v(T) \leq v(S \cup T) \forall S, T \subseteq N \text { and } S \cap T=\varnothing .
$$

It signifies that the two separate coalitions can create at least as much value if they form one large coalition. An allocation $x$ is a vector with $\mathrm{n}$ elements $x_{i}$ that indicate the corresponding payoff of each player. A payoff vector satisfies efficiency if $\sum_{i \in N} x_{i}=v(N)$. Further, an allocation $x$ is called an imputation if $x$ satisfies two constraints: $x_{i} \geq v(i) \forall i \in N$ and efficiency. The set of all imputations of a game $G=(N, v)$ is denoted by $I(N, v)$.

\subsection{Approaches to cooperative game solutions}

Hart et al. (1997) divided cooperative game approaches into core-like and value-like approaches. Core-like approaches give a set of allocations that conform to some general properties of feasible solution. Value-like approaches can serve as feasible solution set to choose from, or a proposition of feasible solution axiomatized.

Core-like approach and the core The Core is a representative core-like approach. For a TU-cooperative game $(N, v)$, the core $C(N, v)$ is defined by equation (2).

$$
\begin{gathered}
C(N, v)=\left\{x \mid \sum_{x_{i} \in I(N, v)} x_{i}=v(N) \text { and } x(S) \geq v(S)\right. \\
\forall S \subseteq N \text { and } x \in I(N, v)\} .
\end{gathered}
$$

As Kannai (1992) illustrated, It is the set of all feasible payoff vectors that no player or coalition can improve upon by acting for themselves. It can be used to verify the stability of specific allocations. The major drawback of the core-like solution is that the core could be empty or non-unique.

Value-like approach and the Shapley Value Due to the complexity of computing and the non-uniqueness of corelike solutions, the value-like solutions, especially the Shapley Value, are more intensively addressed for analyzing collaborations in supply chain management.

Shapley Value is a solution concept evaluating the deserved payoff of player $i$ according to its marginal contributions to all the subsets of $N \backslash\{i\}$. This concept 
is originally proposed in Shapley (1953). In a TUcooperative game $(N, v)$, the Shapley Value is a payoff vector $\phi(v)=\left(\phi_{1}(v), \phi_{2}(v), \ldots \phi_{n}(v)\right)$ verifying certain axioms. The Shapley Value must satisfies four axioms: efficiency, dummy players, symmetry and linearity, which are axiomatized by Hart et al. (1997).

It has been proven that there is always a unique solution that satisfies all four axioms, i.e. the Shapley Value $\phi$. For a game $G=(N, v)$, it can be calculated by the following formula $(3)$ :

$$
\begin{aligned}
\phi_{i}(v)=\sum_{S \subseteq N ; i \in S} \frac{(|N|-|S|) ! \cdot(|S|-1) !}{|N| !} \cdot[v(S)-v(S \backslash\{i\})], \\
\forall i \in N .
\end{aligned}
$$

As shown in the formula above, it is easier to calculate than Core-like solutions, and the Shapley Value of some special game have favorable properties. Béal et al. (2008) has proved that the Shapley Value is a stable imputation for a super-additive TU-Cooperative game. That is why this theory is widely disseminated.

\section{PROPERTIES OF TU-GAME APPLIED TO SUPPLY NETWORKS POOLING}

\subsection{Definition of the coalitions}

For the implementation of pooled network, we should investigate the related cooperative-game-theory issues to set up the cooperation mechanism. The first question: who are players and what are the possible definitions of coalitions.

Since the supply chains pooling is the collaboration among suppliers and retailers, so there are possibilities that either suppliers or retailers take charge of the transportation. Thus there are two approaches: either one of the two groups, group of suppliers or that of retailers, takes charge of the transportation and the group in charge will share the common gain as players of the pooling game; or all suppliers and retailers participate altogether the pooling game, and take each one a share of the common gain. It is the second approach that has been adopted in this work.

The first approach is unworkable since we can easily imagine, if suppliers were to pool their logistics for serving retailers, it would not be long before the latter claimed part of the gains obtained on deliveries and, vice versa, by changing the roles. This would inevitably give rise to secondary sharing out of the gain by negotiation. Therefore, the definition of the pooled logistics systems studied here can be defined by the game $G_{t m}=(N, v)$ with $N=A \cup R$ where $A$ is the set of all suppliers and $R$ is the set of all retailers.

In particular, for a transport problem, we first define that at least one supplier and one retailer are required in a valid coalition. The set of invalid coalitions are written here as $C_{I}$, let $c_{I}=\varnothing, c_{I} \subseteq A$ or $c_{I} \subseteq R$ be the members of $C_{I}$. And the characteristic function of them will equal 0 .
4.2 Properties of the characteristic function in pooled supply networks

In cooperative game theory, the characteristic function $v(S)$ is the value created by the coalition $S$, and this value will be shared by the member players (denoted by $i, \forall i \in$ $S$ ) of this coalition. Given that this work concentrate on logistics pooling, and that the corresponding optimization problem aims at minimization of the sum of transportation cost and carbon tax, the value created by pooling should be the reduction of the total cost. So the characteristic function is defined by $v(S)=I(S)-M(S), \forall S \subseteq N$, where the $I(S)$ and $M(S)$ are the total cost before and after the pooling. All pooling optimizations are computed by the model indicated in Part 2.3.

To determine $v(S)$, it is important to make some clarification about the properties of pooling:

Property 1. Non-pooling in a simple coalition: $I(p)=M(p)$ if $p$ is a coalition of one supplier and one retailer. $P$ denotes the collection of all such simple coalitions $p$.

Property 2. Linearity of costs without pooling: $I(S)=$ $\sum_{p \in P, p \subseteq S} I(p)$;

Property 3. Superiority: pooling does not increase the transportation cost, then $I(S)-M(S) \geq 0$;

Property 4. Economy of scale in pooling: $M\left(S \cup S^{\prime}\right) \leq$ $M(S)+M\left(S^{\prime}\right), S, S^{\prime} \subseteq N$; by this property, it is easy to further prove that the pooling game is a super additive game because $v(S)+v\left(S^{\prime}\right) \leq v\left(S \cup S^{\prime}\right)$.

Consequently, the game corresponding to the pooling of logistics systems $G_{t m}=(N, v)$ studied in this work can be defined as a set of equations (4):

$$
\begin{aligned}
G_{t m}=(N, v): & v\left(c_{I}\right)=0, c_{I}=\varnothing, c_{I} \subseteq A \text { or } c_{I} \subseteq R \\
& v(p)=0, p=\left\{A_{i} \in A, R_{j} \in R\right\} \text { and }|p|=2 ; \\
& v(S) \geq 0, S \subseteq N \text { and } S \notin\left(C_{I} \cup P\right) ;
\end{aligned}
$$

The game $G_{t m}=(N, v)$ is proven to be super-additive as stated in Property 4. The super-additivity means that, by cooperating in the grand coalition, players in the pooling game can achieve the highest cost reduction. Furthermore, this type of game has interesting solution properties. Béal et al. (2008) has proved that the Shapley Value is a stable imputation for a super-additive TU-Cooperative game.

Thus the properties of supply networks pooling game are introduced in subsequent sections. In Part 5, we will investigate a real-world case modeled as pooling game.

\section{A REAL-WORLD CASE STUDY: THE RETAIL LOGISTICS NETWORK IN FRANCE}

The case study in this work is conducted with real flows data provided by Club Déméter (the association of major logistics players in France, www.club-demeter.fr). This support enables us to conduct studies on the basis of a real database of French retail supply chains. 


\subsection{Presentation of the retail logistics pooling game}

From the database provided by partners, we chose four suppliers that have extensive flows of consumer goods from the same location and deliver to the national distribution centers of two retailers, who are in fact common customers of these suppliers. There are thus 4 warehouses $(\mathrm{WH})$ already collocated in the same area and 32 distribution centers (DC) considered in our optimization problem as showed in Fig. 2. The transportation scope studied in this work is between the WHs and the DCs.

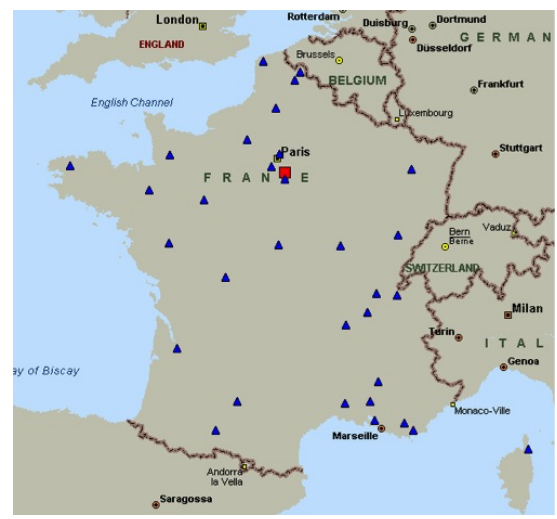

Fig. 2. Location of the logistics sites in the study (Rectangle $=\mathrm{WH}$; Triangle $=\mathrm{DC}$ )

The flows are determined from weekly records over a 33week horizon. Table 1 illustrates the characteristics of the logistics systems in question.

Table 1. Characteristics of the case study flows (ALD/C: Average linear distance / connexion; SDLD: Standard deviation of linear distance; $\mathrm{AF} / \mathrm{CW}$ : Average flows / connexion per week; SDF/W: Standard deviation of flows/ week.)

\begin{tabular}{|c|c|c|c|c|c|c|}
\hline & Sites & Connections & \multicolumn{2}{|c|}{$\begin{array}{l}\text { ALD/C SDLD } \\
(\mathrm{km})\end{array}$} & $\begin{array}{l}\text { AF/CW } \\
\text { (pallet) }\end{array}$ & $\mathrm{SDF} / \mathrm{W}$ \\
\hline $\mathrm{A}$ & & (R1; R2) & & & & \\
\hline A1 & 1 & $5 ; 8$ & 548 & 222 & 26,51 & 37,35 \\
\hline $\mathrm{A} 2$ & 1 & $24 ; 3$ & 399 & 249 & 7,91 & 10,67 \\
\hline A3 & 1 & $21 ; 8$ & 399 & 225 & 68,73 & 39,74 \\
\hline $\begin{array}{c}\mathrm{A} 4 \\
\mathrm{R}\end{array}$ & 1 & $24 ; 8$ & 425 & 244 & 39,44 & 29,96 \\
\hline R1 & 24 & 74 & 391 & 255 & 40,04 & 39,06 \\
\hline $\mathrm{R} 2$ & 8 & 21 & 523 & 150 & 31,5 & 35,37 \\
\hline
\end{tabular}

The flows belonging to different supplier-distributor pairs were classified, so that the pooling schemes of all possible coalitions can be optimized separately to compute the gains can be achieved by the coalitions, i.e. the characteristic function values of all possible coalitions. This pooling game thus modeled consists of $|A|=4$ suppliers and $|R|=2$ retailers $(N=6)$.

\subsection{Optimization results}

As a first step, we need to determine an appropriate tax rate for optimization. We assessed the sensitivity of pooling optimization to the tax rate $r$ by optimizing the grand coalition $N$ with $r \in\{0,20,50,100,200\}\left(€ / \mathrm{t} \mathrm{CO}_{2}\right)$ respectively. The results listed in Table 2 show that the tax rate does not affect the pooling scheme. When the tax rate increases, the transportation scheme keeps always the same. But we can notice that, as the tax rate increases, there will be more reduction of total cost, thus more incentives for pooling.

Table 2. Optimization results of the grand coalition with different tax rates corresponding to independent supply chain operations

\begin{tabular}{lccccc}
\hline Tax rate $(€ / \mathrm{t})$ & 0 & 20 & 50 & 100 & 200 \\
\hline $\begin{array}{l}\text { Reduction of trans- } \\
\text { portation cost }(€)\end{array}$ & 37213 & 37213 & 37213 & 37213 & 37213 \\
\hline $\begin{array}{l}\text { Reduction of } \mathrm{CO}_{2} \\
\text { emission }(\mathrm{t})\end{array}$ & 13.6 & 13.6 & 13.6 & 13.6 & 13.6 \\
\hline $\begin{array}{l}\text { Reduction of Car- } \\
\text { bon tax }(€)\end{array}$ & 0 & 272 & 680 & 1360 & 2720 \\
\hline $\begin{array}{l}\text { Reduction of Total } \\
\text { cost }(€)\end{array}$ & 37213 & 37485 & 37893 & 38573 & 39933 \\
\hline
\end{tabular}

This result is reasonable considering the similar piecewiselinear form of the emission and cost function illustrated in the work of Pan et al. (2010). Since the pooling scheme does not change with different tax rates, we choose the rate $20 € / \mathrm{t}$ in our case study. Then by adopting the optimization model presented in the work of Pan et al. (2010), we optimized the objective function $M I N: C+$ $r \cdot e$ of all possible coalitions respectively, and computed the results of $I(S), M(S)$ and $v(S)$ of valid coalitions $S \subseteq N$ (the $v(S)$ values are listed in Table 3 ), where $I(N)=144286$ and $M(N)=106801$ represent the highest total cost reduction. Thus we can see that the cooperative pooling scheme can achieve $25.98 \%$ reduction of the total cost by players' cooperation in the grand coalition.

Table 3. Optimization results of all possible coalitions with $\mathrm{r}=20 € / \mathrm{t}$

\begin{tabular}{|c|c|c|c|c|c|c|c|c|c|c|c|c|c|c|}
\hline $\mathbf{N}^{\circ}$ & $\begin{array}{l}\text { Coalitions } \\
\end{array}$ & & $\mathrm{v}(\mathrm{M})$ & $\mathrm{N}^{\circ}$ & & Coalitions & & $v(M)$ & $\mathrm{N}^{\circ}$ & & Coalition & & & $v(M)$ \\
\hline S1: & $\mathrm{A} 1$ & R1 & 0 & S16: & $\mathrm{A} 1$ & & R2 & 0 & S31: & $\mathrm{A} 1$ & & $\mathrm{R} 1 \mathrm{R}$ & & 0 \\
\hline S2: & A2 & R1 & 0 & S17: & $\mathrm{A} 2$ & & $\mathrm{R}_{2}$ & 0 & S32: & A2 & & $\mathrm{R} 1 \mathrm{R}$ & R2 & 562 \\
\hline S3: & $\mathrm{A} 3$ & $\mathrm{Rl}$ & 0 & S18: & A3 & & $\mathrm{R} 2$ & 0 & S33: & A3 & & $\mathrm{R} 1 \mathrm{R}$ & R2 & 805 \\
\hline S4: & A4 & $\mathrm{R} 1$ & 0 & s19: & A4 & & $\mathrm{R} 2$ & 0 & S34: & A4 & & $\mathrm{R} 1 \mathrm{R}$ & R2 & 2103 \\
\hline s5: & $\mathrm{A} 1 \mathrm{~A} 2$ & $\mathrm{R} 1$ & 2228 & S20: & Al $\mathrm{A}$ & & $\mathrm{R} 2$ & 1675 & S35: & & & $\mathrm{R} 1 \mathrm{R}$ & R2 & 8615 \\
\hline S6: & $\mathrm{A} 1 \mathrm{~A} 3$ & R1 & 266 & S21: & Al $A$ & & $\mathrm{R} 2$ & 5212 & S36: & A 1 A & & $\mathrm{R} 1 \mathrm{R}$ & R2 & 8741 \\
\hline S7: & $\mathrm{A} 1 \mathrm{~A} 4$ & $\mathrm{R} 1$ & 3241 & S22: & Al $\mathrm{A}$ & & $\mathrm{R} 2$ & 7954 & S37: & Al A & & $\mathrm{R} 1 \mathrm{R}$ & R2 & 13690 \\
\hline s8: & $\mathrm{A} 2 \mathrm{~A} 3$ & R1 & 8535 & S23: & $\mathrm{A} 2 \mathrm{~A}$ & & $\mathrm{R} 2$ & 1675 & S38: & A2 A & & $\mathrm{R} 1 \mathrm{R}=$ & R2 & 10674 \\
\hline s9: & A2 $\mathrm{A} 4$ & R1 & 11764 & S24: & $\mathrm{A} 2 \mathrm{~A}$ & & $\mathrm{R} 2$ & 2124 & S39: & $\mathrm{A} 2 \mathrm{~A}$ & & & R2 & 15928 \\
\hline s10: & A3 A4 & R1 & 9091 & S25: & A3 $\mathrm{A}$ & & $\mathrm{R}_{2}$ & 3383 & S40: & A3 $\mathrm{A}$ & $\mathrm{A} 4$ & $\mathrm{R} 1 \mathrm{R}$ & R2 & 14053 \\
\hline s11: & $\begin{array}{lll}\mathrm{A} 1 & \mathrm{~A} 2 & \mathrm{~A} 3\end{array}$ & $\mathrm{Rl}$ & 11885 & S26: & Al $\mathrm{A}$ & A2 A3 & R2 & 8233 & S41: & Al A & $\mathrm{A} 2 \mathrm{~A} 3$ & $\mathrm{R} 1 \mathrm{R}$ & R2 & 22326 \\
\hline s12: & $\mathrm{A} 1 \mathrm{~A} 2 \mathrm{~A} 4$ & R1 & 13941 & S27: & Al $\mathrm{A}$ & A2 $\mathrm{A} 4$ & $\mathrm{R}_{2}$ & 9980 & S42: & A1 A & $\mathrm{A} 2 \mathrm{~A} 4$ & $\mathrm{R} 1 \mathrm{R}$ & R2 & 26297 \\
\hline S13: & $\mathrm{A} 1 \mathrm{~A} 3 \mathrm{~A} 4$ & $\mathrm{R} 1$ & 12182 & S28: & Al $\mathrm{A}$ & A3 $\mathrm{A} 4$ & R2 & 11033 & S43: & Al $\mathrm{A}$ & A3 A4 & $\mathrm{R} 1 \mathrm{R}$ & R2 & 24822 \\
\hline S14: & $\mathrm{A} 2 \mathrm{~A} 3 \mathrm{~A} 4$ & $\mathrm{R} 1$ & 20911 & S29: & $\mathrm{A} 2 \mathrm{~A}$ & A3 $\mathrm{A} 4$ & $\mathrm{R} 2$ & 5407 & S44: & $\mathrm{A} 2 \mathrm{~A}$ & A3 $\mathrm{A} 4$ & $\mathrm{R} 1 \mathrm{R}$ & R2 & 27494 \\
\hline S15: & $\begin{array}{lllllll}\mathrm{A} 1 & \mathrm{~A} 2 & \mathrm{~A} 3 & \mathrm{~A} & 4\end{array}$ & $\mathrm{Rl}$ & 23271 & s30: & $\mathrm{Al} \mathrm{A}$ & $\mathrm{A} 2 \mathrm{~A} 3 \mathrm{~A} 4$ & $\mathrm{R} 2$ & 13057 & S45: & Al A & & $\mathrm{R} 1 \mathrm{R}$ & R2 & 37485 \\
\hline
\end{tabular}

\subsection{Gain allocation by Shapley Value}

Based on the total cost reductions (characteristic function values) of the valid coalitions, we computed the Shapley Values of all players in the game with grand coalition (listed in Table 4). The Shapley Values are computed by adopting the approach proposed by Hart and Mas-Colell (1989), called the Potentiality approach, which further simplifies the calculation.

Based on these previous results, we can conclude as follows. At first, by cooperating in the grand coalition, players can get the highest common gain, which ensures the incentives to form the grand coalition. Secondly, we verify that the imputation computed by Shapley Value concept lies in the core, which means that such allocation 
Table 4. Gain allocation in the pooling game with grand coalition with $\mathrm{r}=20 € / \mathrm{t}$

\begin{tabular}{|c|c|c|c|c|c|c|}
\hline & A1 & A2 & A3 & $\mathbf{A 4}$ & R1 & R2 \\
\hline $\begin{array}{l}\text { Allocation of } \\
\text { transportation } \\
\text { cost reduction } \\
(€)\end{array}$ & 4374 & 5530 & 5128 & 6965 & 9440 & 5775 \\
\hline $\begin{array}{l}\text { Allocation of } \\
\text { CO2 tax } \\
\text { reduction }(€)\end{array}$ & 32 & 40 & 38 & 52 & 70 & 42 \\
\hline $\begin{array}{l}\text { Shapley Values } \\
\text { of total cost } \\
\text { reduction }(€)\end{array}$ & 4406 & 5570 & 5166 & 7017 & 9510 & 5817 \\
\hline
\end{tabular}

of the common gain is acceptable for all players. Further, since the computation of this imputation considered all players marginal contribution, as the computing procedure of the Shapley Value concept shows, this imputation is reasonable and fair. At last, we can see that the emission tax is also a cooperation incentive, though lack of deterrent effect.

\section{CONCLUSION}

In this article, we introduced firstly an innovative form of logistics cooperation, the supply chains pooling, which minimizes the sum of transportation cost and carbon tax. Then, we proposed a cooperative-game-theory approach as the cooperative mechanism for the implementation of such pooling scheme.

We confirmed the validity of this pooling scheme in reducing both the transportation cost and the carbon tax by showing that, a cost-reduction rate of $25.98 \%$ has been achieved in the case study of the retail logistics network in France. Also, after the supply-chains-pooling game being proved a super-additive game, the imputation computed by the Shapley Value concept has been proved to be fair and stable as to the marginal-contribution consideration and the collective rationality of all players. Such gainsharing scheme can effectively promote the formation of the logistics-cooperation alliances, thus improve the logistics productivity.

There are some drawbacks of this paper, which can be overcome by our ongoing research works. The first is the absence of cooperation cost in the game design. The second is about the modeling of different bargaining power of players. Then we will investigate the application of our pooling scheme in big game with many players.

\section{REFERENCES}

Ballot, E. and Fontane, F. (2010). Reducing transportation $\mathrm{CO}_{2}$ emissions through pooling of supply networks: perspectives from a case study in french retail chains. Production Planning \& Control, 21(6), 640-650.

Béal, S., Durieu, J., and Solal, P. (2008). Farsighted coalitional stability in tu-games. Mathematical Social Sciences, 56(3), 303-313.

CITEPA (2009). Emissions dans l'air en france. Technical report, Centre Interprofessionel Technique d'Etudes de la Pollution Atmospherique., Paris.

Cruijssen, F., Cools, M., and Dullaert, W. (2007). Horizontal cooperation in logistics: opportunities and im- pediments. Transportation Research Part E: Logistics and Transportation Review, 43(2), 129-142.

Cruijssen, F. and Salomon, M. (2004). Empirical study: Order sharing between transportation companies may result in cost reductions between 5 to 15 percent. Discussion Paper.

Ergun, O., Kuyzu, G., and Savelsbergh, M. (2007). Shipper collaboration. Computers \& Operations Research, 34(6), 1551-1560.

Hall, R. (1987). Consolidation strategy: Inventory, vehicles and terminals. Journal of Business Logistics, 8(2), 5773.

Hart, S. and Mas-Colell, A. (1989). Potential, value, and consistency. Econometrica: Journal of the Econometric Society, 589-614.

Hart, S., Mas-Colell, A., and Division, N.A.T.O.S.A. (1997). Cooperation: game-theoretic approaches. Springer.

Kannai, Y. (1992). The core and balancedness. In Handbook of game theory with economic applications, volume 1, chapter 12, 355-395. Elsevier.

Léonardi, J. and Baumgartner, M. (2004). $\mathrm{CO}_{2}$ efficiency in road freight transportation: Status quo, measures and potential. Transportation Research Part D: Transport and Environment, 9(6), 451-464.

McKinnon, A., Ge, Y., and Leuchars, D. (2003). Analysis of transport efficiency in the uk food supply chain. Technical report, Logistics Research Centre Heriot-Watt University, Edinburgh.

McKinnon, A. and Piecyk, M. (2009). Measurement of $\mathrm{CO}_{2}$ emissions from road freight transport: A review of uk experience. Energy policy, 37(10), 3733-3742.

Pan, S. (2010). Contribution à la définition et à l'évaluation de la mutualisation de châ̂nes logistiques pour réduire les émissions de $\mathrm{CO}_{2}$ du transport: application au cas de la grande distribution. Ph.D. thesis, MINES ParisTech.

Pan, S., Ballot, E., and Fontane, F. (2010). The reduction of greenhouse gas emissions from freight transport by pooling supply chains. International Journal of Production Economics.

Pooley, J. and Stenger, A. (1992). Modeling and evaluating shipment consolidation in a logistics system. Journal of Business Logistics, 13, 153-153.

Shapley, L. (1953). A value for n-person games. In Contributions to the Game Theory, Vol. II. Princeton Univ Pr.

Shapley, L. (1971). Cores of convex games. International Journal of Game Theory, 1(1), 11-26.

Vanek, F. and Morlok, E. (2000). Improving the energy efficiency of freight in the united states through commodity-based analysis: justification and implementation. Transportation Research Part D: Transport and Environment, 5(1), 11-29.

Von Neumann, J., Morgenstern, O., Rubinstein, A., and Kuhn, H. (2007). Theory of games and economic behavior. Princeton Univ Pr. 